\title{
N-Ethylmaleimide-Sensitive Factor Is Required to Organize Functional Exocytotic Microdomains in Paramecium
}

\author{
Marine Froissard,* Roland Kissmehl, ${ }^{\dagger}$ Jean-Claude Dedieu, ${ }^{*}$ Tadeusz Gulik-Krzywicki, * \\ Helmut Plattner ${ }^{\dagger}$ and Jean Cohen*,1 \\ * Centre de Génétique Moléculaire, Centre National de la Recherche Scientifique, 91198 Gif-sur-Yvette Cedex, France and \\ ${ }^{\dagger}$ University of Konstanz, Department of Biology, 78457 Konstanz, Germany
}

\begin{abstract}
In exocytosis, secretory granules contact plasma membrane at sites where microdomains can be observed, which are sometimes marked by intramembranous particle arrays. Such arrays are particularly obvious when membrane fusion is frozen at a subterminal stage, e.g., in neuromuscular junctions and ciliate exocytotic sites. In Paramecium, a genetic approach has shown that the "rosettes" of intramembranous particles are essential for stimulated exocytosis of secretory granules, the trichocysts. The identification of two genes encoding the $\mathrm{N}$-ethylmaleimide-sensitive factor (NSF), a chaperone ATPase involved in organelle docking, prompted us to analyze its potential role in trichocyst exocytosis using a gene-silencing strategy. Here we show that NSF deprivation strongly interferes with rosette assembly but does not disturb the functioning of exocytotic sites already formed. We conclude that rosette organization involves ubiquitous partners of the fusion machinery and discuss where NSF could intervene in this mechanism.
\end{abstract}

$\mathrm{E}^{\mathrm{x}}$ XPORT of molecules from eukaryotic cells follows a secretory pathway from the endoplasmic reticulum to the plasma membrane, which is carried out by vesicle budding from donor compartments and fusion with target compartments. The process of membrane fusion had long been a black box until complementary approaches, biochemistry in neurendocrine tissues and genetics in yeast, led to the discovery of essential protein partners. Numerous proteins and protein complexes have been discovered in these studies. A central one, $\mathrm{N}$-ethylmaleimide-sensitive factor (NSF), has been found as a ubiquitous ATPase involved in membrane fusion events throughout intracellular traffic, including the terminal step of exocytosis at the plasma membrane. Together with soluble NSF attachment proteins (SNAPs), NSF acts as a chaperone in the disassembly of a tight complex of SNAP receptors (SNAREs). SNAREs are trans-membrane proteins, which are associated in trans configuration between the two membranes to be fused (SÖLlner et al. 1993a,b; Hanson et al. 1997; Weber et al. 2000). Yet the precise docking/fusion/recycling step at which NSF acts is still under debate (UnGERMANN $e t$ al. 1998; Bock and SCHEller 1999; JAHN and SüDHOF 1999). Part of the discrepancies comes from the different levels of the traffic at which membrane fusion is

Sequence data from this article have been deposited with the EMBL/GenBank Data Libraries under accession nos. AJ347751 and AJ347752 for PtNSF1 and PtNSF2, respectively.

${ }^{1}$ Corresponding author: Centre de Génétique Moléculaire, Centre National de la Recherche Scientifique, Ave. de la Terrasse, 91198 Gifsur-Yvette Cedex, France. E-mail: jean.cohen@cgm.cnrs-gif.fr studied. In yeast, the most extensively studied cell type, molecular mechanisms are given for homotypic fusion of vacuolar membranes (WICKNER and HaAs 2000) and for heterotypic membrane fusion during exocytosis (GROTE et al. 2000). Due to differences in recycling after fusion in these pathways, the step at which NSF dissociates SNAREs can be different.

To address this question, the study of Paramecium has two main advantages. First, it is one of the rare cell models easily amenable to genetics, an approach with which new genes can be discovered without any a priori assumptions about their primary structure, location, or function. Second, in Paramecium, trichocyst exocytotic membrane fusion can be isolated from previous steps of the traffic pathway (reviewed by Vayssié et al. 2000). After biogenesis, trichocysts migrate to the plasma membrane and are anchored to predetermined sites. When examined by freeze fracture and transmission electron microscopy, the organization of a microdomain can be observed at each exocytosis site in the plasma membrane and between the two membranes to be fused. A ring of particles delineates the exocytosis site, and a rosette of particles, as well as a connecting material between trichocyst and cell membrane, marks the focal point where membrane fusion will be initiated (Beisson et al. 1976; Olbricht et al. 1984; Pouphile et al. 1986). These particle arrays could be the landmark of possible lipidic microdomains, as recently described (LANG et al. 2001). The system remains frozen in this prefusion state, until external stimulation occurs (Figure 1). Strong evidence that these microdomains are essential for membrane fusion has been provided by the isolation and study 


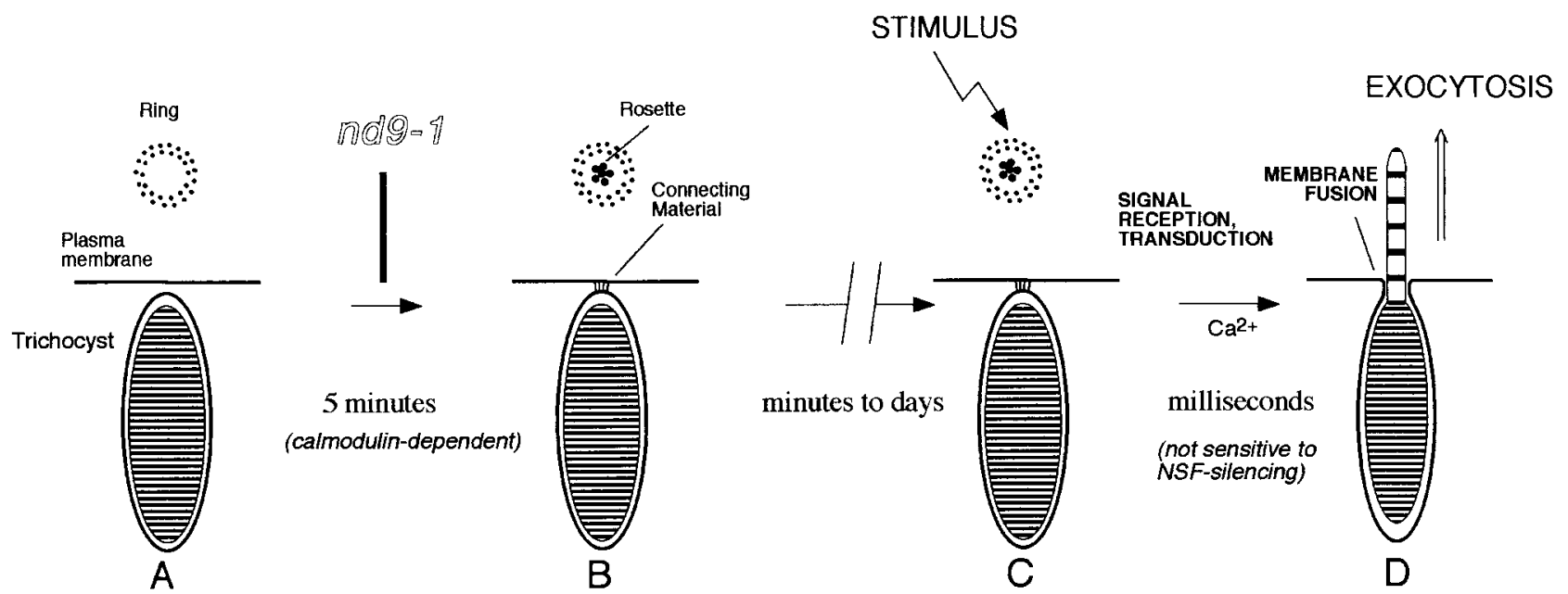

FIgURE 1.-Schematic representation of the trichocyst exocytotic pathway at the plasma membrane in Paramecium. (A-D) Four stages are represented on the scheme. Exocytotic sites with (A) positioned or (B) attached trichocysts or (C and D) undergoing exocytosis are shown. On the top are schematized the corresponding arrays of intramembranous particles visible in freeze-fracture electron microscopy. After trichocyst insertion at its site, small intramembranous particles are recruited to form rosette particles at the center of preexisting rings and the connecting material assembles between trichocyst and plasma membrane, in a calmodulin-dependent way (Kerboeuf et al. 1993). This requires only $\sim 5$ min after the arrival of a trichocyst, but for the ensemble of the docking sites in a cell, hours are required since trichocysts are docked nonsynchronously (PLATTNER et al. 1993). The fact that this assembly occurs hours after a shift to permissive temperature in the mutant nd9-1 is not the result of weaker efficiency of the machinery in the mutant but of the fact that the mutant Nd9-1p molecules await a physiological change in membrane lipid composition, which takes hours to occur (BeIsson et al. 1980; Froissard et al. 2001). Exocytosis sites then remain unchanged, even for days (BeIsson et al. 1976), until a stimulus (C) triggers exocytosis, which occurs within milliseconds (D), in a way not sensitive to NSF silencing (R. Kissmehl, M. Froissard, H. Plattner, M. Momayezi and J. Cohen, unpublished results).

of thermosensitive "nondischarge" $(n d)$ mutants, which lack these arrays correlatively with their deficiency in exocytosis. The recent characterization of two NSF genes in Paramecium (Dessen et al. 2001; R. Kissmehl, M. Froissard, H. Plattner, M. Momayezi and J. Cohen, unpublished results), PtNSF1 and PtNSF2, provided new tools to link ultrastructural features pertinent to trichocyst exocytosis to current concepts of exocytosis in other systems.

Using a gene-silencing approach, we showed that NSF is essential for membrane traffic, in particular for the endoplasmic reticulum to Golgi transition, for endocytosis, and phagocytosis (R. Kissmehl, M. Froissard, H. Plattner, M. Momayezi and J. Cohen, unpublished results). Apparently, no effect on trichocyst exocytosis could be detected in wild-type cells in which PtNSF genes have been silenced. In this work, we developed a strategy to bypass the early defects of PtNSF gene silencing and focus on the last steps of microdomain organization, using the thermosensitive mutant nd9-1, which is able to assemble rosettes when shifted to permissive temperature, independently of cell growth or even protein synthesis (Beisson et al. 1980; Froissard et al. 2001). We showed that NSF action is essential for rosette assembly, suggesting that SNARE disassembly could be a prerequisite for this process.

\section{MATERIALS AND METHODS}

Strains and culture conditions: The wild-type strain was Paramecium tetraurelia stock d4-2, derived from stock 51 (SonNEBORN 1974). The thermosensitive nd9-1 mutant (permissive temperature $<20^{\circ}$, nonpermissive one $>25^{\circ}$ ), previously described (BEISSON et al. 1980; FroIsSARD et al. 2001), belongs to the $n d$ category of mutants in which trichocysts are attached to the cortex, but in which membrane fusion is impaired. Cells were grown at $27^{\circ}$ or $18^{\circ}$, as indicated, in grass infusion (wheat grass powder; Pines International, Lawrence, KS), bacterized with Klebsiella pneumoniae the day before use, and supplemented with $0.4 \mu \mathrm{g} / \mathrm{ml} \beta$-sitosterol (Sonneborn, 1970).

Monitoring exocytosis: To visualize individual cells with their own discharged trichocysts, a saturated solution of picric acid is used as a fixing secretagogue. Discharged trichocysts remain clustered around the cell surface and can be visualized easily under dark-field light microscopy with a $10 \times$ objective.

Homology-dependent gene silencing: The silencing of a particular gene can be triggered experimentally in Paramecium by microinjection of the corresponding coding DNA, without flanking sequences, into the macronucleus of wild-type cells (Ruiz et al. 1998; Galvani and Sperling 2001). PtNSF gene silencing was performed in either wild-type or nd9-1 mutant cells by microinjection into the macronucleus of concentrated PCR DNA corresponding to the open reading frame of the PtNSF1 gene. Since silencing effect is dose-dependent and we do not accurately control the amount of DNA introduced through microinjection, we took advantage of the clear blockage in food vacuole formation to recognize and isolate silenced cells; see below.

PCR on genomic DNA for microinjection: The open reading 
frame of PtNSF1 was amplified from total wild-type DNA (prepared from log-phase cultures according to DUHARcourT et al. 1995), using polymerase chain reaction made with the Expand Long Template PCR system kit (Roche Diagnostics, Mannheim, Germany). The reaction $(50 \mu \mathrm{l})$, adjusted to a concentration of nucleotides corresponding to the Paramecium A + T rich genome composition (740 nM dATP and dTTP; $260 \mathrm{~nm} \mathrm{dCTP} \mathrm{and} \mathrm{dGTP),} \mathrm{contained} 150 \mathrm{ng}$ of genomic DNA, 50 pmol of each primer, and 3 units of polymerase mix. The primers used were as follows: primer 1, $5^{\prime}$-TCTAACTAT TACCAGTTGCTC-3'; primer 2, 5'-GGTGATTCATAATCACT GTAG-3'.

Amplification was performed with 1 cycle of denaturation $\left(92^{\circ}, 2 \mathrm{~min}\right) ; 10$ cycles of denaturation $\left(92^{\circ}, 10 \mathrm{sec}\right)$, annealing $\left(55^{\circ}, 30 \mathrm{sec}\right)$, and extension $\left(68^{\circ}, 3 \mathrm{~min} 30 \mathrm{sec}\right)$; and then 20 cycles of denaturation $\left(92^{\circ}, 10 \mathrm{sec}\right)$, annealing $\left(55^{\circ}, 30 \mathrm{sec}\right)$, and extension $\left(68^{\circ}, 3 \mathrm{~min} 30 \mathrm{sec}+15 \mathrm{sec} /\right.$ cycle $)$, with a final extension $\left(68^{\circ}, 7 \mathrm{~min}\right)$.

PCR amplification of the $\gamma$-tubulin open reading frame was performed as described by Ruiz et al. (1999).

The products obtained were purified by the QIAquick PCR purification kit (QIAGEN, Chatsworth, CA), filtered on MillexGV (0.22 $\mu \mathrm{m}$; Millipore, Bedford, CA), precipitated, and resuspended in water at a final concentration between 10 and $30 \mu \mathrm{g} / \mu \mathrm{l}$.

DNA microinjection: Microinjection of filtered concentrated PCR DNA was made under an inverted Nikon phasecontrast microscope, using a Narishige micromanipulation device and Eppendorf air-pressure microinjector. For silencing experiments in the wild type, cells were treated with a solution of aminoethyldextran (PlatTNer et al. 1984) at $0.01 \%$ to stimulate trichocyst exocytosis before microinjection, to avoid further discharge that could disturb the microinjection procedure. Cells recover their full exocytotic capacity within $7 \mathrm{hr}$, a much shorter time than the minimal 18-24 hr required for silencing to appear. After microinjection, cells were cloned at $27^{\circ}$ (or $18^{\circ}$, as indicated) and followed for growth rate, global phenotype, phagocytosis ability, and exocytosis. For silencing experiments on the nd9-1 mutant, cells grown at $27^{\circ}$ (deficient for exocytosis) were directly microinjected without prior treatment. Cells were cloned and cultured various times at $27^{\circ}$ before shift to $18^{\circ}$ (see RESUlts).

Monitoring phagocytotic activity: Living cells were observed $10 \mathrm{~min}$ after addition of India ink in the culture medium. Food vacuoles appear as black dots in the cytoplasm under the dissecting microscope. Control cells make approximately one food vacuole per minute and therefore appear full of black dots. In the case of phagocytosis inhibition, cells remain totally white.

Freeze-fracture electron microscopy: As NSF-silenced cells rapidly lose their viability, few cells are available for freeze fracturing. We therefore developed a procedure in which small pools of cells could be processed by transfer of cells in different solutions and onto copper plates for rapid freezing. To prevent unwanted stimulation during the fixation step, the cell medium was adjusted to $20 \mathrm{~mm} \mathrm{MgCl}_{2}$ with a $1 \mathrm{~m}$ stock solution for $3 \mathrm{~min}$ before transfer into $1 \%$ glutaraldehyde, $10 \mathrm{~mm}$ Na-phosphate buffer $\mathrm{pH} 7.0$ for $1 \mathrm{hr}$ at room temperature and two washes in the same buffer without glutaraldehyde. Fixation was used in this experiment since it allows rosette particles to partition into the plasmatic fracture face, like the other particles (double ring) of the exocytotic site (LEFORTTrAN et al. 1978). Cells were placed onto hydrophilic $10-\mu \mathrm{m}-$ thick round copper plates and then rapidly covered by another plate. The rest of the treatment, including freeze fracture and electron microscopy, was as previously described by BonNEMAIN et al. (1992).

\section{RESULTS}

NSF deprivation does not interfere with membrane fusion when microdomains are already assembled: Two PtNSF genes sharing 87\% identity at the DNA level and 94\% identity at the protein level have been identified: PtNSF1 and PtNSF2 (R. Kissmehl, M. Froissard, H. Plattiner, M. Momayezi and J. Cohen, unpublished results). In Paramecium, silencing experiments, conducted by microinjection into the macronucleus of concentrated PCR DNA corresponding to the open reading frame of the PtNSF1 gene (see MATERIALS AND METHODS), are supposed to affect the expression of both PtNSF1 and PtNSF2 genes, since cosilencing is assumed for genes sharing $\geq 85 \%$ identity in nucleotide sequence [extrapolated from RNAi experiments in the nematode (PARRISH et al. 2000; also discussed by Ruiz et al. 1998)]. To assess the role of NSF in trichocyst membrane fusion, silencing experiments were performed on wild-type cells. Twenty-four hours after microinjection, silenced cells maintained at $27^{\circ}$ have a recognizable phenotype, as shown by R. Kissmehl, M. Froissard, H. Plattner, M. Momayezi and J. Cohen (unpublished results). They have undergone only two fissions (instead of four in the uninjected control), appear morphologically altered, are unable to form food vacuoles, as assayed with India ink, and display altered overall membrane traffic in electron microscopy. Longer incubations provoke increase of the altered phenotype and eventually cell death within $48 \mathrm{hr}$ postmicroinjection (this time is doubled if cultures are performed at $18^{\circ}$ ). Therefore, PtNSF genes appear to be essential in Paramecium.

When monitored with picric acid $24 \mathrm{hr}$ at $27^{\circ}$ after microinjection and even later, cells displayed normal exocytosis (R. Kissmehl, M. Froissard, H. Plattwer, M. Momayezi and J. Cohen, unpublished results). Small pools of cells, selected for efficient silencing by inability to form food vacuoles, were processed for rapid freezing and freeze fracture. Observation of the replica in electron microscopy showed that all silenced cells displayed normal rosettes, as illustrated in Figure 2, b-e. The silencing of NSF was therefore unable to interfere with the exocytotic process in cells where the machinery is already in place (Figure 1, C and D) before silencing is installed. In addition, this indicates that NSF silencing is unable to destabilize rosettes that are already assembled. This is in convergence with the fact that the trichocyst exocytosis sites are very stable, once built, and can remain functional, even under conditions in which they would not assemble, e.g., nonpermissive temperature in thermosensitive nd mutants (BEISson et al. 1980; Kerboeuf et al. 1993).

PtNSF gene silencing blocks exocytosis recovery in the nd9-1 mutant: The lack of effect of PtNSF silencing on preformed exocytosis sites lead to the question of its effect on the assembly of this site (Figure 1, A and 


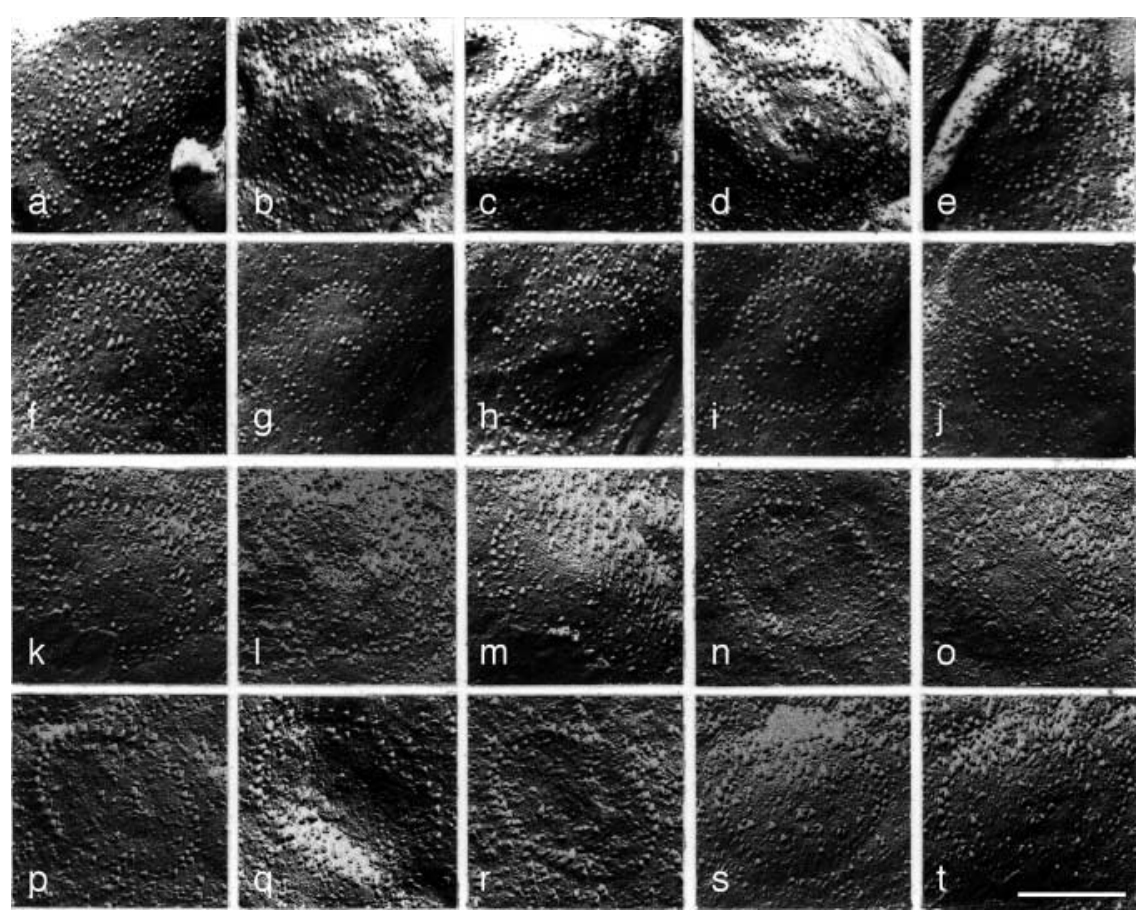

FIGURE 2.-NSF silencing effect on rosette assembly in freeze-fracture replicas. (a) Typical wild-type exocytosis site with a rosette of 13-nm intramembranous particles located at the center of a double ring of 8-nm particles (Plattner and Zingsheim 1983; Beisson et al. 1976). (b-e). No difference is seen in exocytotic sites of wild-type cells after NSF silencing. (f-j) Exocytotic sites of $n d 9-1$ cells $24 \mathrm{hr}$ after temperature shift from $27^{\circ}$ to $18^{\circ}$. Rosettes are variably assembled according to the site observed, translating the fact that exocytosis recovery is not fully completed. $(\mathrm{k}-\mathrm{t})$ Exocytotic sites of NSF-silenced nd9-1 cells during exocytosis recovery. No rosette is assembled at all. Only one or two particles can be seen in some sites. Bar, $200 \mathrm{~nm}$.
B). We first tried to follow the recovery of normal exocytosis in PtNSF-silenced wild-type cells, when sites are rebuilt after complete discharge of trichocysts using the vital secretagogue aminoethyldextran. However, the block in membrane traffic and in trichocyst biogenesis induced by PtNSF silencing (R. Kissment, M. FroisSard, H. Plattner, M. Momayezi and J. Cohen, unpublished results) precludes this experiment. In addition, the very fragile NSF-silenced cells are killed by the aminoethyldextran treatment.

To study rosette assembly under NSF deprivation, we took advantage of the genetic possibilities of Paramecium, with its panel of exocytosis mutants $(n d)$ blocked in membrane fusion (VAyssié et al. 2000) in which we found the ideal one to address this question. In the thermosensitive mutant $n d 9-1$, we can disconnect rosette assembly from early steps of trichocyst biogenesis, migration, and attachment to the cortex. Indeed, when nd9-1 cells are shifted from nonpermissive $\left(27^{\circ}\right)$ to permissive $\left(18^{\circ}\right)$ temperature, rosette particles can be assembled, even in the absence of cell growth (stationary phase) and of protein synthesis (presence of puromycin). This indicates that rosette components are present in the membrane of the mutant, even at $27^{\circ}$, but that the mutational defect prevents their assembly and possible interactions of these components with the cytosolic protein Nd9-1p (BEISSON et al. 1980; FroIsSARd et al. 2001). PtNSF gene-silencing experiments were therefore undertaken in the nd9-1 mutant, during rosette assembly and exocytosis recovery, to isolate this particular step from all the other membrane fusion events upstream of it.
The first goal was to synchronize two different kinetics, the establishment of PtNSF gene silencing and the recovery of exocytosis upon temperature shift. After several attempts (Figure 3), a protocol was obtained in which the appearance of cells unable to form food vacuoles in silenced cells coincided with one-half of the recovery of exocytosis capacity in control nd9-1 cells shifted to permissive temperature. Nd9-1 mutant cells, equilibrated for at least 3 days at the nonpermissive temperature of $27^{\circ}$ to have a fully expressed phenotype, were microinjected in their macronucleus with the coding DNA corresponding to the PtNSF1 gene. Cells were cultured at this temperature for another $16 \mathrm{hr}$ before being shifted to $18^{\circ}$. Twenty-four hours later, transformed cells with silenced phenotype (no food vacuole formation) were obtained. These cells were unable to discharge their trichocysts (Figure 3, experiment 3).

To be sure that this defect in exocytosis recovery was not due simply to general metabolism alteration in silenced cells committed to die, we made a control experiment using $\gamma$-tubulin-silenced cells. Indeed, such cells stop duplicating their ciliary basal body, yield smaller cells after division, and eventually die after two fissions (Ruiz et al. 1999). nd9-1 cells preequilibrated at $27^{\circ}$ were microinjected with $\gamma$-tubulin-silencing DNA, left for $24 \mathrm{hr}$ at $27^{\circ}$, and transferred to $18^{\circ}$ when silencing was already expressed, as assessed by the small size of the cells. Twenty-four hours later, both control and silenced cells underwent exocytotic recovery, indicating that this process was unaffected when cells were close to death for a reason other than PtNSF gene silencing.

Effect of PtNSF gene silencing at the ultrastructural 


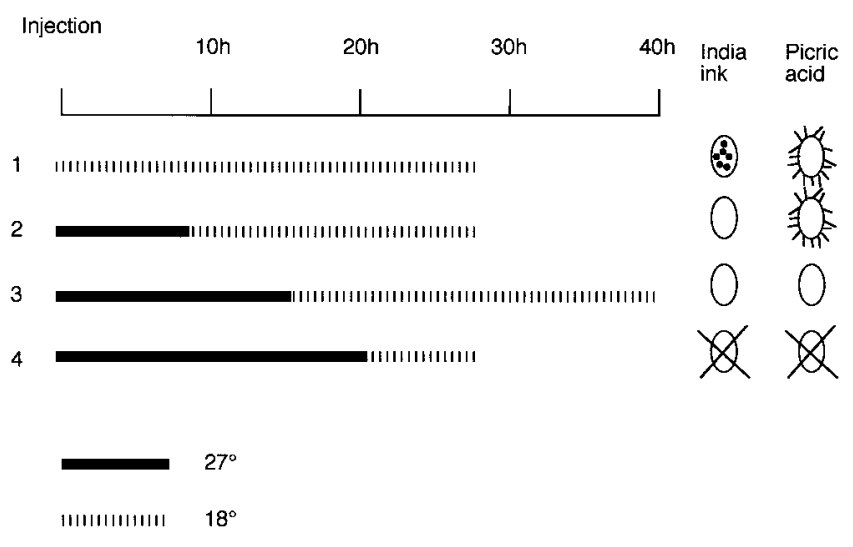

Figure 3.-Synchronization of PtNSF gene silencing with exocytosis recovery in $n d 9-1$ cells. $n d 9-1$ cells preequilibrated at $27^{\circ}$ for 3 days were microinjected with $P t N S F$ gene-silencing DNA and shifted at various times from $27^{\circ}$ to $18^{\circ}$ after microinjection. In all cases, uninjected control $n d 9-1$ cells (not shown) were able to ingest India ink in food vacuoles and in experiments 1-3, partial exocytosis of 50-300 trichocysts was recovered. The time of exposure at $18^{\circ}$ in experiment 4 was too short to initiate recovery. PtNSF gene silencing was inefficient in experiment 1 because the full time at $18^{\circ}$ slowed down its establishment. PtNSF gene silencing was efficient in experiment 2 (as revealed by the incapacity to form food vacuoles) but appeared too late compared to exocytosis recovery. In experiment 3, we obtained (i) a good synchrony between silencing establishment and exocytosis recovery in control cells and (ii) a clear-cut negative effect of NSF silencing on trichocyst exocytosis. In experiment 4 , the cells died before the test, suggesting that silencing was already triggered after $21 \mathrm{hr}$ at $27^{\circ}$ and that this is rapidly lethal for cells submitted to a temperature shift, which induces thorough membrane traffic.

level in the nd9-1 mutant: The data accessible using freeze fracture of Paramecium plasma membrane are twofold. They permit determination of the proportion of sites occupied by a trichocyst and, among these sites, checking of the appearance of the rosettes. The state of occupancy of exocytotic sites can be determined easily since parenthesis-shaped particle arrays denote empty sites, free of trichocysts, whereas ring-shaped arrays indicate the presence of a trichocyst anchored at the site (BEIsson et al. 1976). We counted the numbers of parentheses and rings in control and PtNSF1-silenced cells submitted to the temperature shift. Out of 119 observable sites in controls, $36(30 \%)$ were parentheses and $83(70 \%)$ were rings. In silenced cells, out of 136 sites, $81(60 \%)$ were parentheses and $55(40 \%)$ were rings. When silencing is established, no new trichocyst can be formed and attached to the cortex [because the traffic is blocked very early, at the step of vesicle budding from the endoplasmic reticulum (R. Kissmehl, M. Froissard, H. Plattner, M. Momayezi and J. Cohen, unpublished results)]. Hence, the total number of rings remains constant upon residual cell growth and division, yielding a decreased proportion in each descent cell. The fact that the number of rings in silenced cells is

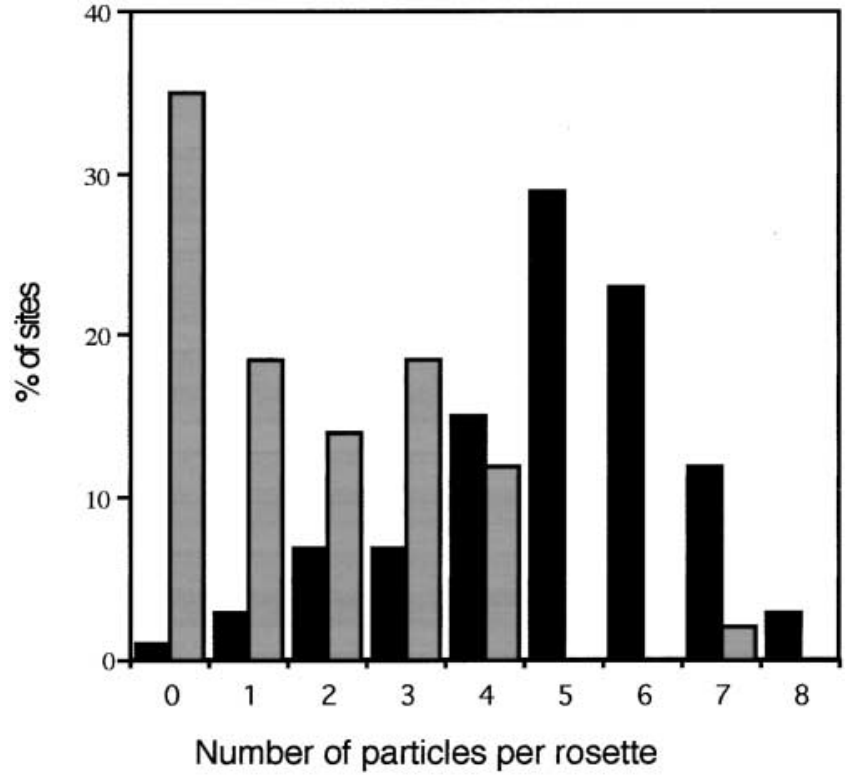

Figure 4.-Effect of PtNSF gene silencing on rosette assembly in $n d 9-1$ cells shifted to $18^{\circ}$. The histogram plots the percentage of rings against the number of rosette particles they contain. Solid bars show the control nd9-1 strain (73 sites) and shaded bars show the PtNSF-silenced ones (49 sites).

roughly one-half that of control suggests that only one cell division has occurred after silencing establishment.

Second, exocytotic sites with attached trichocysts (rings) normally display a rosette of approximately eight particles in wild-type cells, indicating that the site is functional and can undergo membrane fusion. Mutant sites in nd cells, such as $n d 9-1$ at $27^{\circ}$, are devoid of rosette particles. From an intermediate situation in which only a few particles are assembled, for instance, during temperature shifts of thermosensitive $n d$ mutants, it has been assumed that more than four particles per rosette are needed to allow exocytotic membrane fusion (LEFORT-TRAN et al., 1981). It was crucial to know whether the failure of trichocyst discharge recovery in silenced nd9-1 cells was due to a failure of rosette assembly or to a downstream block. Among the ring-shaped sites, 73 were analyzable for presence of rosette particles in control cells and 49 in PtNSF-silenced cells. The repartition of the number of rosette particles per site clearly shows that rosette formation is inhibited in PtNSFsilenced cells (Figure 4), as illustrated in Figure 2, $\mathrm{f}-\mathrm{j}$ (control cells) and k-t (PtNSF-silenced cells). The fact that these cells do not discharge any trichocyst also confirms the observation that more than four rosette particles are necessary to allow membrane fusion.

\section{DISCUSSION}

Paramecium is a unicellular organism with many differentiated functions in the same cytoplasm and displays a complex role of membrane traffic orchestrated through 


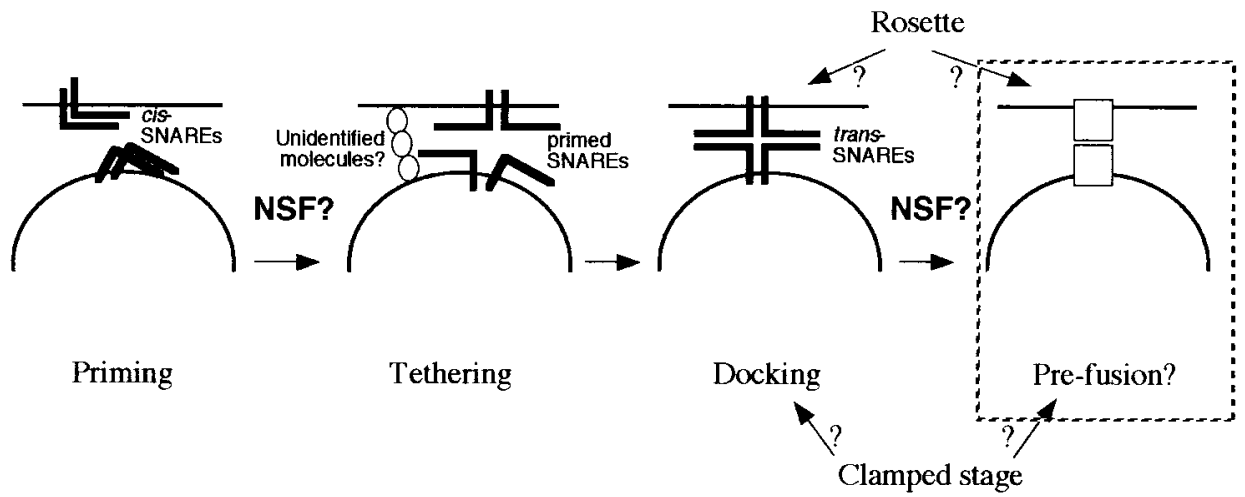

Figure 5.-Molecular events proposed for trichocyst docking and membrane fusion. The cartoon integrates features generally accepted or hypothesized to explain events in the scheme of rosette assembly in Paramecium, as shown in Figure 1, A and B. Concomitant or successive steps of SNARE priming (cisSNARE complex disassembly) and trichocyst tethering to the plasma membrane precede docking (transSNARE interactions). As discussed in the text, protein complexes downstream from trans-SNARE assembly have been postulated in some systems (Ungermann et al. 1998; PETERS et al. 2001) and are represented here as a box. Therefore, NSF may have two possible sites of action: (i) to disrupt cis-SNAREs before tethering/ docking and (ii) to disrupt trans-SNARE downstream interactions, if they do exist, to perform membrane fusion. The stage that is clamped (primed) in Paramecium, identifiable by the presence of a rosette, is either the trans-SNARE complex or any downstream complex. In either case, the rosette is a visualization of the presence of such a complex.

the NSF-associated machinery (R. KISSMEHL, M. FroisSard, H. Plattner, M. Momayezi and J. Cohen, unpublished results). The question remained to know whether an NSF-associated machinery was also involved in the terminal step of regulated exocytosis, namely trichocyst discharge, and more precisely in the assembly of specialized arrays defining a microdomain visible in electron microscopy, the rosette. Previous work did not give any clues in this direction since the few ND genes already cloned by functional complementation all appeared to be novel for membrane fusion (ND7, SkOURI and Cohen 1997; ND9, Froissard et al. 2001). In addition, NSF silencing in wild-type cells did not give any effect on stimulated exocytosis of trichocysts already attached to the cortex (R. KissmeHL, M. Froissard, H. Plattner, M. Momayezi and J. Cohen, unpublished results; this work).

The existence of Paramecium conditional mutants such as nd9-1, in which rosette assembly can be specifically manipulated, permits unique insights into the role of essential proteins, such as NSF, in the very last steps of exocytotic membrane fusion. nd9-1 cells silenced for NSF at the restrictive temperature were unable to recover exocytosis and to assemble rosettes when shifted to the permissive temperature. Two conclusions can be drawn from these results. First, like most other membrane fusion events, trichocyst exocytosis requires an NSF/SNAP/SNARE machinery. Second, at least one NSF-dependent stage lies upstream from rosette assembly whereas the steps downstream from rosette assembly up to membrane fusion seem less sensitive to NSF deprivation (see the synthetic scheme in Figure 5), although it is not excluded that NSF tightly bound to exocytotic sites remain active during silencing experiments.

The direct role of NSF is to disassemble complexes between v-SNAREs and t-SNAREs, although the precise step within the sequence of docking-priming-fusionrecycling at which the disassembly takes place is still being debated (HANSON et al. 1997; UNGERMANN et al. 1998; Bock and Scheller 1999; Jahn and SüDhoF 1999). Two main classes of membrane fusion occur in the cell. One, called homotypic, involves identical partner membranes (as is the case with vacuoles in yeast); the other one, called heterotypic, involves different membranes (e.g., endoplasmic reticulum with Golgi membrane, secretory vesicle with plasma membrane). In homotypic fusion, it is known that v- and t-SNARE complexes exist in cis on the membrane and have to be dissociated to allow interaction in trans. This is less evident in heterotypic fusion, for which such complexes need to be disassembled only after fusion, when they become cis-complexes on the mixed membrane.

Here, we found NSF action to be essential for rosette assembly, indicating that SNARE complex disassembly occurs prior to rosette particle interactions. Two possible targets are discussed for the action of NSF in trichocyst exocytosis: cis-SNARE complexes that may exist before membrane interaction or trans-SNARE complexes assembled during this interaction.

On the one hand, there is strong evidence for a priming role of NSF and $\alpha$-SNAP through cis-SNARE complex disassembly (HANson et al. 1997; Xu et al. 1999). This role is supported by the observations of WeBER et al. (2000) that only cis-SNARE complexes can be disassembled by NSF and $\alpha$-SNAP, in this case after membrane fusion. Such a role is possible in trichocyst exocytosis, if cis-SNARE complexes actually exist on trichocyst and/or plasma membranes, although it is heterotypic membrane fusion. In this case, rosette particles would reflect the presence of trans-SNARE complexes.

On the other hand, other studies plead in favor of a role of trans-SNARE complex disassembly before membrane fusion. First, mutant $\alpha$-SNAPs that prevent the stimulation of the ATPase activity of NSF, but not the binding to the SNARE complex, prevent disruption of this complex, and exocytotic membrane fusion, al- 
though the wild-type molecule drives both events (BARNARD et al. 1997). Second, in homotypic fusion of vacuolar vesicles in yeast, trans-SNARE complexes have been shown to be disassembled by NSF and $\alpha$-SNAP (UNGERMANN et al. 1998), without interference with docking at the plasma membrane or downstream membrane fusion. In this case, rosette particles would be postSNARE complexes.

Recently, it has been proposed that complexes between V0 subunits of proton pump ATPases in both membranes represent a calmodulin-sensitive post-SNARE fusion machinery (PETERs et al. 2001). In this context, the hypothesis of a role of NSF in trans-SNARE disassembly before ultimate proteolipid channel interactions seems very attractive for trichocyst exocytosis. Rosette particles visible in fractured membranes are more likely to correspond to membrane proteins with several transmembrane domains such as V0 than to SNARE proteins with single transmembrane helices. In addition, the assembly of the rosette is dependent on calmodulin (KERBOEUF et al. 1993).

The connections between membranes visible in electron microscopy might be not restricted to Paramecium, as they could correspond to a transient step in membrane fusion in other models. Indeed, such intermembrane links and intramembranous particles have sometimes been caught (Aunis et al. 1979; Heuser et al. 1979; Chandler and Heuser 1980). This aspect, which makes it possible to focus on the mechanisms occurring in a space limited to a few cubic nanometers within the last milliseconds encompassing triggered membrane fusion, highlights the interest in Paramecium. Owing to the synergy between genetics and postgenomics, using gene silencing, Paramecium appears now to be the ideal model to unravel pre- and post-SNARE events in heterotypic membrane fusion.

We thank Janine Beisson, France Koll, and Linda Sperling for critical reading of the manuscript. Financial support from the Deutsche Forschungsgemeinschaft to H.P. and from the Microbiology Program of the Ministère de la Recherche to J.C. are gratefully acknowledged.

\section{LITERATURE CITED}

Aunis, D. J., R. Hesketh and G. Devilliers, 1979 Freeze-fracture study of chromaffin cell during exocytosis: evidence for connections between the plasma membrane and secretory vesicles and for movements of plasma membrane associated particles. Cell Tissue Res. 197: 433-441.

Barnard, R., A. Morgan and R. Burgoyne, 1997 Stimulation of NSF ATPase activity by $\alpha$-SNAP is required for SNARE complex disassembly and exocytosis. J. Cell Biol. 139: 875-883.

Beisson, J., M. Lefort-Tran, M. Pouphile, M. Rossignol and B. SATIR, 1976 Genetic analysis of membrane differentiation in Paramecium. Freeze-fracture study of the trichocyst cycle in wild type and mutant strains. J. Cell Biol. 69: 126-143.

Beisson, J., J. Cohen, M. Lefort-Tran, M. Pouphile and M. RossigNOL, 1980 Control of membrane fusion in exocytosis. Physiological studies on a Paramecium mutant blocked in the final step of the trichocyst extrusion process. J. Cell Biol. 85: 213-227.

Bock, J., and R. Scheller, 1999 SNARE proteins mediate lipid bilayer fusion. Proc. Natl. Acad. Sci. USA 96: 12227-12229.
Bonnemain, H., T. Gulik-Krzywicki, C. Grandchamp and J. Cohen, 1992 Interactions between genes involved in exocytotic membrane fusion in Paramecium. Genetics 130: 461-470.

Chandler, D. E., and J. E. Heuser, 1980 Arrest of membrane fusion events in mast cells by quick-freezing. J. Cell Biol. 86: 666-674.

Dessen, P., M. Zagulski, R. Gromadka, H. Plattner, R. Kissmehl et al., 2001 Paramecium genome survey: a pilot project. Trends Genet. 17: 306-308.

Duharcourt, S., A. Butler and E. Meyer, 1995 Epigenetic selfregulation of developmental excision of an internal eliminated sequence on Paramecium tetraurelia. Genes Dev. 9: 2065-2077.

Froissard, M., A. Keller and J. Cohen, 2001 ND9P, a novel protein with Armadillo-like repeats involved in exocytosis: physiological studies using allelic mutants in Paramecium. Genetics 157: 611620.

Galvani, A., and L. Sperling, 2001 Transgene-mediated post-transcriptional gene silencing is inhibited by 3 ' non-coding sequences in Paramecium. Nucleic Acids Res. 29: 4387-4394.

Grote, E., C. M. Carr and P. J. Novick, 2000 Ordering the final events in yeast exocytosis. J. Cell Biol. 151: 439-451.

Hanson, P., R. Roth, H. Morisaki, R. Jahn and J. Heuser, 1997 Structure and conformational changes in NSF and its membrane receptor complexes visualized by quick-freeze/deep-etch electron microscopy. Cell 90: 523-535.

Heuser, J. E., T. S. Reese, M. J. Dennis, Y. Jan, L. Jan et al., 1979 Synaptic vesicle exocytosis captured by quick freezing and correlated with quantal transmitter release. J. Cell Biol. 81: 275-300.

Jahn, R., and T. C. Südhof, 1999 Membrane fusion and exocytosis. Annu. Rev. Biochem. 68: 863-911.

Kerboeuf, D., A. Leberre, J. C. Dedieu and J. Cohen, 1993 Calmodulin is essential for assembling links necessary for exocytotic membrane fusion in Paramecium. EMBO J. 12: 3385-3390.

Lang, T., D. Bruns, D. Wenzel, D. Riedel, P. Holroyd et al., 2001 SNAREs are concentrated in cholesterol-dependent clusters that define docking and fusion sites for exocytosis. EMBO J. 20: 22022213.

Lefort-Tran, M., T. Gulik, H. Plattner, J. Beisson and W. WiessNER, 1978 Influence of cryofixation procedures on organization and partition of intramembranous particles, pp. 146-147 in Proceedings of the Ninth International Congress of Electron Microscopy, Vol. II, edited by J. STurgess. Microscopical Society of Canada, Toronto.

Lefort-Tran, M., K. Aufderheide, M. Pouphile, M. Rossignol and J. Beisson, 1981 Control of exocytotic processes: cytological and physiological studies of trichocyst mutants in Paramecium tetraurelia. J. Cell Biol. 88: 301-311.

Olbricht, K., H. Plattner and H. Matt, 1984 Synchronous exocytosis in Paramecium cells. II. Intramembranous changes analysed by freeze-fracturing. Exp. Cell Res. 151: 14-20.

Parrish, S., J. Fleenor, S. Xu, C. Mello and A. Fire, 2000 Functional anatomy of a dsRNA trigger: differential requirement for the two trigger strands in RNA interference. Mol. Cell 6: 10771087.

Peters, C., M. Bayer, S. Bühler, J. Andersen, M. Mann et al., 2001 Trans-complex formation by proteolipid channel in the terminal phase of membrane fusion. Nature 409: 581-588.

Plattner, H., and H. P. Zingsheim, 1983 Electron microscopic methods in cellular and molecular biology. Subcell. Biochem. 9: $1-236$.

Plattner, H., H. Matt, H. Kersken, B. Haacke and R. Sturzl, 1984 Synchronous exocytosis in Paramecium cells. I. A novel approach. Exp. Cell Res. 151: 6-13.

Plattner, H., R. Pape and G. Knoll, 1993 Synchronization of different steps of the secretory cycle in Paramecium tetraurelia: trichocyst exocytosis, exocytosis-coupled endocytosis, and intracellular transport, pp. 123-148 in Membrane Traffic in Protozoa, edited by H. Plattner. JAI Press, Greenwich, CT/London.

Pouphile, M., M. Lefort-Tran, H. Plattner, M. Rossignol and J. Beisson, 1986 Genetic dissection of the morphogenesis of exocytosis in Paramecium. Biol. Cell 56: 151-162.

Ruiz, F., L. Vayssié, C. Klotz, L. Sperling and L. Madeddu, 1998 Homology-dependent gene silencing in Paramecium. Mol. Biol. Cell 9: 931-943.

Ruiz, F., J. Beisson, J. Rossier and P. Dupuis-Williams, 1999 Basal body duplication in Paramecium requires gamma-tubulin. Curr. Biol. 9: 43-46. 
Skouri, F., and J. Cohen, 1997 Genetic approach to regulated exocytosis using functional complementation in Paramecium: identification of the ND7 gene required for membrane fusion. Mol. Biol. Cell. 8: 1063-1071.

Söllner, T., S. Whiteheart, M. Brunner, H. Erdjument-Bromage, S. GERomanos et al., 1993a SNAP receptors implicated in vesicle targeting and fusion. Nature 362: 318-324.

Söllner, T., M. Bennet, S. Whiteheart, R. Scheller and J. RothMAN, 1993b A protein assembly-disassembly pathway in vitro that may correspond to sequencial steps of synaptic vesicle docking, activation, and fusion. Cell 75: 409-418.

Sonneborn, T. M., 1970 Methods in Paramecium research. Methods Cell Physiol. 4: 242-335.

Sonneborn, T. M., 1974 Paramecium aurelia, pp. 469-594 in Handbook of Genetics, Vol. 2, edited by R. C. KInG. Plenum Press, New York.
Ungermann, C., K. Sato and W. Wickner, 1998 Defining the functions of trans-SNARE pairs. Nature 396: 543-548.

Vayssié, L., F. Skouri, L. Sperling and J. Cohen, 2000 Molecular genetics of regulated secretion in Paramecium. Biochimie 82: 269 288.

Weber, T., F. Parlati, J. McNew, R. Johnston, B. Westermann et $a l ., 2000$ SNAREpins are functionally resistant to disruption by NSF and alpha-SNAP. J. Cell Biol. 149: 1063-1072.

Wickner, W., and A. HAas, 2000 Yeast homotypic vacuole fusion: a window on organelle trafficking mechanisms. Annu. Rev. Biochem. 69: 247-275.

Xu, T., U. Ashery, R. Burgoyne and E. Neher, 1999 Early requirement for $\alpha$-SNAP and NSF in the secretory cascade in chromaffin cells. EMBO J. 18: 3293-3304.

Communicating editor: S. L. AlleN 